\title{
Amyand's Hernia: A Case Report and Review of Japanese Literature
}

\author{
Kenji Furukawa and Kurodo Koshino \\ Department of Surgery, Tama-Nanbu Chiiki Hospital, Tokyo Metropolitan Health \\ and Medical Treatment Corporation
}

\begin{abstract}
Amyand's hernia is an extremely rare type of inguinal hernia that involves herniation of the appendix. Here, we report a case of Amyand's hernia in a 77-year-old man. The patient had developed a painful swelling in the right inguinal region 3 years ago; the swelling could be manually reduced but became increasingly painful over time. The hernia was intraoperatively identified as an external inguinal hernia containing the ileocecum and an uninflamed appendix. Only weak adhesions were present between the appendix and hernial sac; therefore, the appendix could be easily separated and was replaced within the abdominal cavity. The mesoappendix was not involved, and an appendectomy was not required. The inguinal hernia was repaired in a radical operation using a direct Kugel patch. The patient's postoperative course was favorable, and he was discharged 3 days after the surgery. Postoperative infection of the surgical site did not occur.
\end{abstract}

Key words: Amyand's hernia, inguinal hernia, appendix

\section{Introduction}

Adult inguinal hernia is a frequently encountered condition in surgical practice, but herniation of the appendix - a condition called Amyand's hernia - is extremely rare. Here, we report a case of Amyand's

Received: August 24, 2010/Accepted: October 24, 2010 Correspondence to: Kenji Furukawa

Department of Surgery, Tama-Nanbu Chiiki Hospital, Tokyo Metropolitan Health and Medical Treatment Corporation 1-2-1 Nakazawa, Tama-city, Tokyo 206-0036, Japan hernia and review the relevant literature.

\section{Case Report}

The patient was a 77-year-old man with a painful swelling in his right inguinal region. In November 2004, he had undergone a subtotal gastrectomy for the resection of gastric cancer. He noticed a painful swelling in his right inguinal region in January 2007. The swelling in the groin increased in size 2-3 times in a year; at that time, the swelling could be manually reduced. However, in about November 2009, the bulge in the right groin area became more prominent while standing or moving, because of a gradual increase in size and pain, the patient was hospitalized for surgical repair of the hernia in March, 2010.

A physical examination at admission yielded the following findings: height, $169 \mathrm{~cm}$; weight, $58 \mathrm{~kg}$; temperature, $36.2{ }^{\circ} \mathrm{C}$; and blood pressure, $170 / 90 \mathrm{~mm}$ $\mathrm{Hg}$. An enlargement was detected in the right inguinal region.

The results of initial blood tests were within normal limits. Abdominal computed tomography (CT) showed a soft tissue shadow in the subcutaneous fatty tissue of the anterior abdominal wall in the right lower quadrant. On the basis of the CT findings, we diagnosed an inguinal hernia, but no appendiceal impaction was detected (Fig. 1). The patient then underwent surgery to correct the hernia. Upon incising the external oblique aponeurosis, the hernial sac was found to protrude through the inguinal ring, displacing the inferior epigastric vessels and indicating that this was an external inguinal hernia. The hernia sac was palpated to determine its contents and whether it communicated with the abdominal cavity. Upon palpation, a moderately firm, funicular structure was detected. We then carefully incised 


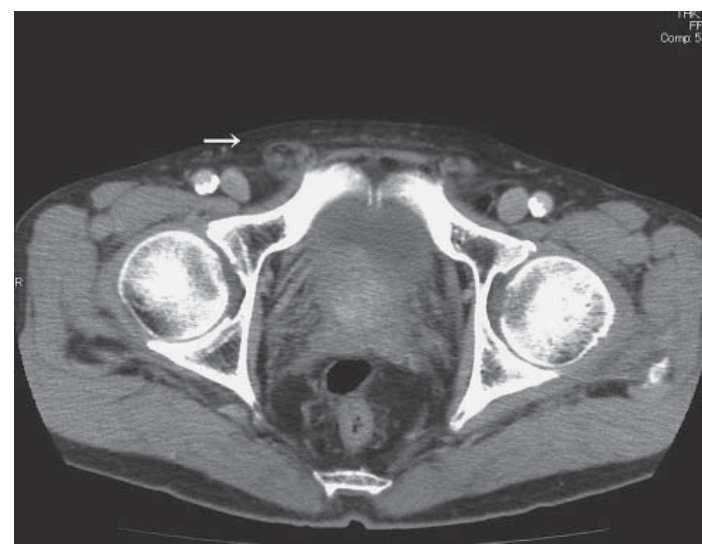

Fig. 1 Abdominal computed tomography: A small right inguinal hernia is seen, but its contents - the appendix are not clearly visualize.

the hernia sac, and observed the ileocecum and a normal, uninflamed, long appendix; the mesoappendix was not involved. On the basis of these findings, we diagnosed an Amyand's hernia (Fig. 2). The appendix had adhered to the hernial sac but was not inflamed. We therefore separated the appendix from the hernial sac and replaced it in the abdominal cavity. We then performed a hernioplasty using a direct Kugel patch. The patient's postoperative course was good, and he was discharged 3 days after the surgery.

\section{Discussion}

The appendix is an extremely rare component of inguinal hernias; the first such hernia was reported by Amyand et al. in $1736^{1)}$. Wakeley et al. ${ }^{2)}$ have reported that in a series of 1232 inguinal hernias, only 12 were Amyand's hernias (0.97\%), and that associated appendicitis and incarceration occurred in only 4 cases. In addition, inflammation of the hernial sac because of acute appendicitis has been reported to occur in $0.13 \%-0.19 \%$ of cases ${ }^{2}$.

We searched Ichushi Web for articles containing the keywords "inguinal hernia, appendix, the impaction." We found 60 reports, including ours, of Amyand's hernia published between 1983 and June 2010 (Table 1 ). A distinct male predilection for Amyand' $\mathrm{s}$ hernia was noted, with the sex ratio being approximately 5:1; the average patient age was 62.6 years. Three patients presented with ileus; all patients had a swelling in the right inguinal region; and many

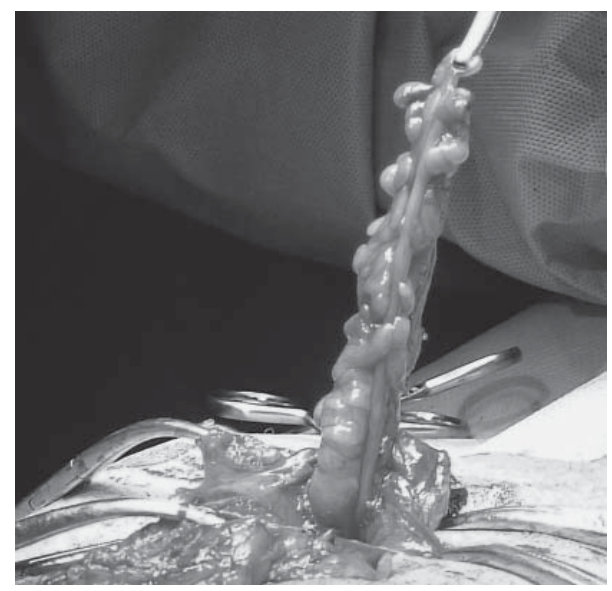

Fig. 2 Operative findings: The hernial sac is opened. Weak adhesions are seen, but there is no inflammation of the appendix.

experienced groin aches. However, findings specific for appendicitis were not reported. Inflammatory reaction was detected in 29 of 34 case reports in which laboratory findings had been mentioned. Impacted inguinal hernia was preoperatively diagnosed in all but 4 patients. The presence of the appendix in the hernial sac was preoperatively determined in only 13 patients. Appendiceal enlargement was noted in 2 patients. In the present case, palpation of the hernial sac during the operation indicated the presence of a funicular structure, possibly the appendix. We therefore opened the hernial sac carefully so as not to damage the appendix. Further, retrospective examination of the preoperative CT scan suggested the presence of a funicular structure in the hernial sac, but a definitive preoperative diagnosis was difficult. Thus, Amyand's hernia is often diagnosed during surgical repair of an inguinal hernia. However, because appendiceal impaction can be diagnosed preoperatively and because of the utility of CT imaging ${ }^{3,4)}$, it may be possible to diagnose Amyand's hernia preoperatively when a hollow lamellar structure terminating in the cecum is detected on abdominal CT.

The treatment of Amyand's hernia involves a hernioplasty and may involve an appendectomy. The indication for an appendectomy should be based on intraoperative findings such as inflammation of the appendix, incarceration of the appendix, severity of adhesions, and mobility of the appendix. If appendi- 
Table 1 Reported cases of Amyand's hernia in Japan

\begin{tabular}{|c|c|c|c|c|c|c|c|c|}
\hline Year & Reporter & Age & Sex & $\begin{array}{l}\text { Preoperative } \\
\text { diagnosis }\end{array}$ & $\begin{array}{l}\text { Inflammatory } \\
\text { reaction }\end{array}$ & $\begin{array}{l}\text { Surgery } \\
\text { approaches }\end{array}$ & $\begin{array}{l}\text { Appen- } \\
\text { decotomy }\end{array}$ & $\begin{array}{l}\text { Operation } \\
\text { (hernia) }\end{array}$ \\
\hline 1985 & Kubota & 3 & $M$ & Appendicitis & $(-)$ & laparotomy & $(+)$ & IIRR \\
\hline 1989 & Nishina & 65 & $\mathrm{~F}$ & $\mathrm{RIHI}$ & $(+)$ & gro+lapa & $(+)$ & IIRR \\
\hline 1989 & Kuwahara & 81 & $\mathrm{~F}$ & $\mathrm{RIHI}$ & $(+)$ & gro+lapa & $(+)$ & Bassini \\
\hline 1990 & Komuro & 0 & $M$ & $\mathrm{RIHI}$ & $(+)$ & groin & $(+)$ & $\mathrm{RIH}$ \\
\hline 1990 & Tanaka & 88 & $M$ & $\mathrm{RIHI}$ & $(+)$ & groin & $(+)$ & $\mathrm{RIH}$ \\
\hline 1993 & Imai & 42 & $\mathrm{~F}$ & $\mathrm{RIHI}$ & $(-)$ & gro+lapa & $(+)$ & Bassini \\
\hline 1994 & Ishihara & 60 & $M$ & $\mathrm{RIHI}$ & $(+)$ & & $(+)$ & McVay \\
\hline 1994 & Kajimoto & 83 & $M$ & $\mathrm{RIHI}$ & & & $(+)$ & $\mathrm{RIH}$ \\
\hline 1995 & Kazui & 63 & $M$ & Recurrent RIHI & & groin & $(+)$ & $\mathrm{RIH}$ \\
\hline 1998 & Uchida & 36 & $M$ & $\mathrm{RIHI}$ & $(-)$ & groin & $(+)$ & IPTR \\
\hline 1998 & Hirano & 0 & $M$ & $\mathrm{RIHI}$ & $(-)$ & groin & $(+)$ & \\
\hline 1999 & Koide & 71 & $\mathrm{~F}$ & $\begin{array}{l}\text { RIHI, abdominal } \\
\text { wall abscess }\end{array}$ & $(+)$ & gro+lapa & $(+)$ & $\mathrm{RIH}$ \\
\hline 1999 & Masuyama & 80 & $M$ & $\begin{array}{l}\text { Recurrent } \\
\text { RIHI (Appe) }\end{array}$ & $(-)$ & groin & $(+)$ & IPTR \\
\hline 1999 & Kihana & 69 & M & RIHI (Appe) & $(+)$ & groin & $(+)$ & IPTR \\
\hline 2000 & Tamura & 85 & $\mathrm{~F}$ & Appendicitis & $(+)$ & gro+lapa & $(+)$ & $\mathrm{RIH}$ \\
\hline 2000 & You & 52 & $M$ & Appendicitis & $(+)$ & & & \\
\hline 2001 & Sakakibara & 72 & $M$ & $\mathrm{RlHI}$ & $(+)$ & gro+lapa & ICR & Mesh \\
\hline 2001 & Inagi & 65 & $M$ & $\mathrm{RIHI}$ & & gro+lapa & $(+)$ & IPTR \\
\hline 2002 & Kawai & 43 & $M$ & $\mathrm{RIH}$ & $(-)$ & groin & $(+)$ & MP \\
\hline 2002 & Kishibuchi & 82 & $M$ & $\mathrm{RIH}$ & $(+)$ & gro+lapa & $(+)$ & PHS \\
\hline 2002 & Shimizu & 82 & $\mathrm{~F}$ & & $(+)$ & & $(+)$ & $\mathrm{RIH}$ \\
\hline 2002 & Shimizu & 74 & $\mathrm{M}$ & RIHI (Appe) & & & $(+)$ & MP \\
\hline 2002 & Hayakawa & 77 & $\mathrm{M}$ & $\mathrm{RIHI}$ & & groin & $(+)$ & $\mathrm{RIH}$ \\
\hline 2002 & Souma & 77 & $M$ & $\mathrm{RIHI}$ & $(+)$ & groin & $(+)$ & IPTR \\
\hline 2003 & Ueda & 92 & $\mathrm{~F}$ & RIHI (Appe) & & gro+lapa & $(+)$ & \\
\hline 2003 & Shimogo & 55 & $M$ & RIHI (Omen) & & groin & $(+)$ & $\mathrm{RIH}$ \\
\hline 2003 & Shimogo & 52 & $M$ & Cord hydrocele & & groin & $(+)$ & $\mathrm{RIH}$ \\
\hline 2003 & Ueno & 70 & $\mathrm{M}$ & $\mathrm{RIHI}$ & $(+)$ & groin & $(+)$ & IPTR \\
\hline 2004 & Morohashi & 73 & $\mathrm{~F}$ & RIHI (Appe) & $(+)$ & gro+lapa & $(+)$ & $\mathrm{HRL}$ \\
\hline 2004 & Shitegawara & 0 & M & $\mathrm{RIHI}$ & $(+)$ & & $(+)$ & $\mathrm{HRL}$ \\
\hline 2005 & Ikeda & 0 & $\mathrm{M}$ & $\mathrm{RIHI}$ & $(+)$ & groin & $(+)$ & $\mathrm{HRL}$ \\
\hline 2005 & Tanioka & 64 & $\mathrm{M}$ & RIHI (Appe) & & & & \\
\hline 2006 & Wada & 0 & $M$ & & & & $(+)$ & $\mathrm{RIH}$ \\
\hline 2006 & Ariyoshi & 90 & $\mathrm{~F}$ & $\mathrm{RIHI}$ & & laparotomy & $(+)$ & $\mathrm{RIH}$ \\
\hline 2006 & Sato & 87 & $M$ & $\begin{array}{l}\text { Recurrent } \\
\text { RIHI (Appe) }\end{array}$ & & & $(+)$ & TF \\
\hline 2006 & Mizunuma & 80 & M & RIH (Cecum) & $(-)$ & groin & $(+)$ & DKP \\
\hline 2007 & Aoba & 78 & $\mathrm{M}$ & RIHI (Appe) & $(+)$ & groin & $(+)$ & McVay \\
\hline 2007 & Sakai & 67 & $\mathrm{M}$ & $\mathrm{RIHI}$ & $(+)$ & groin & $(+)$ & MP \\
\hline 2007 & Yonezawa & 61 & $\mathrm{M}$ & RIHI (Omen) & $(+)$ & groin & $(+)$ & Bassini \\
\hline 2007 & Suwa & 71 & $\mathrm{~F}$ & RIHI (Appe) & $(+)$ & gro+lapa & $(+)$ & $\mathrm{RIH}$ \\
\hline 2007 & Hosono & 88 & $M$ & $\mathrm{RIHI}$ & $(+)$ & groin & ASR & McVay \\
\hline 2007 & Hanashiro & 70 & $\mathrm{M}$ & $\mathrm{RIHI}(\mathrm{SI})$ & $(+)$ & & & MP \\
\hline 2008 & Yoshikazu & 47 & $\mathrm{M}$ & $\mathrm{RIHI}$ & $(-)$ & laparotomy & $(+)$ & Kugel \\
\hline 2008 & Iwama & 68 & $M$ & $\mathrm{RIHI}$ & $(+)$ & laparotomy & $(+)$ & \\
\hline 2008 & Matsuoka & 54 & $M$ & $\mathrm{RIHI}$ & $(+)$ & groin & $(+)$ & MP \\
\hline 2008 & Kurio & & & $\mathrm{RIHI}$ & $(-)$ & groin & $(-)$ & PHS \\
\hline 2008 & Kurio & & & RIHI (Appe) & $(+)$ & groin & $(+)$ & McVay \\
\hline 2009 & Aoki & 81 & $M$ & Recurrent RIHI & $(+)$ & gro+lapa & $(+)$ & Marcy \\
\hline 2009 & Nozaki & 70 & $M$ & $\mathrm{RIHI}$ & $(-)$ & gro+lapa & $(+)$ & IPTR \\
\hline 2009 & Watanabe & 60 & $\mathrm{M}$ & LIHI (Cecum) & $(-)$ & groin & $(+)$ & IPTR \\
\hline 2009 & Inoue & 77 & $M$ & $\mathrm{RIHI}$ & $(+)$ & groin & $(+)$ & MP \\
\hline 2009 & Horiike & 69 & $M$ & $\mathrm{RIHI}$ & $(+)$ & groin & $(+)$ & IPTR \\
\hline 2009 & Maesawa & 48 & M & $\mathrm{RIHI}$ & $(+)$ & gro+lapa & $(+)$ & \\
\hline 2009 & Yoshida & 69 & $\mathrm{M}$ & $\mathrm{RIHI}$ & $(+)$ & groin & $(+)$ & IPTR \\
\hline 2009 & Ariyoshi & 90 & $\mathrm{~F}$ & RIHI (Appe) & $(+)$ & laparotomy & $(+)$ & IIRR \\
\hline 2009 & Ariyoshi & 81 & $M$ & RIHI (Appe) & $(-)$ & groin & $(+)$ & MP \\
\hline 2009 & Ohtsu & 50 & $M$ & RIHI (Appe) & $(+)$ & gro+lapa & $(+)$ & IPTR \\
\hline 2009 & Maeno & 72 & $M$ & $\mathrm{RIHI}$ & $(-)$ & groin & $(-)$ & $\mathrm{RIH}$ \\
\hline 2009 & Yoshida & 69 & $M$ & $\mathrm{RIHI}$ & $(+)$ & groin & $(+)$ & IPTR \\
\hline 2010 & Our case & 77 & $M$ & $\mathrm{RIH}$ & $(-)$ & groin & $(+)$ & DKP \\
\hline
\end{tabular}

$\mathrm{RIHI}$ : Right inguinar hernia incarceration, SI : Small intestine, gro+lapa : groin+laparotomy, ASR : Appendix segmental resection, MP : Mesh plug, IIRR: Inner inguinal ring reefing, HRL : High rank ligation, TF : tension free, RIH : Repair of inguinal hernia 
citis is absent, if the hernial sac does not show any appendiceal adhesions and the appendix can slide within the sac, or if only the tip of the appendix is within the hernial sac and can be easily reduced, then only a radical inguinal hernia repair without an appendectomy should be performed. In the case of our patient, about half of the appendix had adhered to the hernial sac, but the appendix was not inflamed and only minor adhesions were present. We therefore performed only inguinal repair and not appendectomy. Whereas it is thought with adaption of the appendectomy because appendicitis may be caused by influence of inflammation by the hernioplasty and by the appendiceal abrasion operation when appendix stick together for hernia. Of 50 case reports in which the surgical approach had been mentioned, both groin surgery and laparotomy were performed in 15 , only the former was performed in 30 , and only the latter was performed in 5 . The indication of abdominal surgery depended on the perioperative findings. Of 55 patients who underwent appendectomy, prophylactic resection was performed in 12 patients, and the tension-free method was used in 5 patients. In 1 patient, infection of the surgical site occurred in the early postoperative period requiring removal of the artificial materials used for hernia repair ${ }^{5}$. In another patient, the appendix was not inflamed and was therefore replaced within the abdominal cavity; however, this patient subsequently developed appendicitis ${ }^{6}$. Thus, the efficacy of appendectomy during the repair of Amyand's hernia in the absence of appendiceal inflammation is unclear. However, we think that prophylactic appendectomy should not be performed owing to the associated risks of infection and other complications.

Even when the tension-free method was used with prostheses such as a mesh, the frequency of wound infection was very high, approximately $50 \%^{7)}$, and hence, surgeons often opted for iliopubic tract repair or the McVay method ${ }^{8.9)}$. However, the tension-free method with prostheses such as a mesh plug and the
Kugel patch has been successfully used for the treatment of incarcerated Amyand's hernias in which both the appendix and mesoappendix were inflamed. Further analysis is required to determine the appropriate surgical treatment of incarcerated Amyand's hernias with inflammation of the appendix and mesoappendix.

In the 1960s, $\mathrm{Carey}^{10)}$ reported that 3 of 6 patients with perforation of the vermiform appendix died postoperatively; however, the postoperative outcomes in recent years have been more favorable.

Although inguinal hernia is a very common condition, surgeons should exercise caution while treating inguinal hernias that contain funicular structures and impacted inguinal hernias without symptoms of ileus.

\section{References}

1) Hutchinson R: Amyand's hernia. J R Soc Med 86 : 104-105, 1993

2) Wakeley CPG, Long DSc: Hernia of the vermiform appendis. A record of sixteen personl cease. Lancet $2: 1282-1284,1938$

3) Suwa T, Sakurai J, Aoki K, et al: A case of incarcerated inguinal hernia of the appendix (Amyand's Hernia) diagnosed by preoperative CT scan. J Jpn Surg Assoc 68:2398-2402, 2007

4) Masuyama M, Nagase Y, Fukuda K, et al: Recurrent Hernia of the Vermiform Appendix. JSAEM 19 : 1013-1016, 1999

5) Hanashiro N, Matsuura F, Teruya N, et al: A case of incarcerated inguinal hernia of the appendix. J Jpn Surg Assoc 68:890, 2007

6) Ofili OP: Simultaneous appendectomy and inguinal herniorrhaphy could be beneficial. Ethiop Med J 29 : 37-38, 1991

7) Thomas WEG, Vowles KDG, Williamson RCN: Appendicitis in external hernia. Ann R Coll Surg Engl $64: 121-122,1982$

8) Kihana E, Kurisu S, Hatta T, et al: A case of acute appendicitisin an inguinal hernia. J Jpn Surg Assoc $60: 2423-2425,1999$

9) Uchida M, Kanamori H, Yamaguchi E, et al: A case of appendicial infarction in incarcerated inguinal hernia. J Jpn Surg Assoc 59 : 1419-1422, 1998

10) Carey LC: Acute sppendicitis occurring in hernias: A report of 10 cases. Surgery 61 : 236-238, 1967 